\title{
Whole genome amplification approach reveals novel polyhydroxyalkanoate synthases (PhaCs) from Japan Trench and Nankai Trough seawater
}

\author{
Choon Pin Foong ${ }^{1,2}$, Nyok-Sean Lau ${ }^{1,3}$, Shigeru Deguchi ${ }^{4}$, Takashi Toyofuku ${ }^{4}$, Todd D Taylor ${ }^{5}$, Kumar Sudesh ${ }^{2,3^{*}}$ \\ and Minami Matsui ${ }^{i^{*}}$
}

\begin{abstract}
Background: Special features of the Japanese ocean include its ranges of latitude and depth. This study is the first to examine the diversity of Class I and II PHA synthases (PhaC) in DNA samples from pelagic seawater taken from the Japan Trench and Nankai Trough from a range of depths from $24 \mathrm{~m}$ to $5373 \mathrm{~m}$. PhaC is the key enzyme in microorganisms that determines the types of monomer units that are polymerized into polyhydroxyalkanoate (PHA) and thus affects the physicochemical properties of this thermoplastic polymer. Complete putative PhaC sequences were determined via genome walking, and the activities of newly discovered PhaCs were evaluated in a heterologous host.

Results: A total of 76 putative phaC PCR fragments were amplified from the whole genome amplified seawater DNA. Of these 55 clones contained conserved PhaC domains and were classified into 20 genetic groups depending on their sequence similarity. Eleven genetic groups have undisclosed PhaC activity based on their distinct phylogenetic lineages from known PHA producers. Three complete DNA coding sequences were determined by IAN-PCR, and one PhaC was able to produce poly(3-hydroxybutyrate) in recombinant Cupriavidus necator $\mathrm{PHB}^{-} 4$ (PHB-negative mutant).

Conclusions: A new functional PhaC that has close identity to Marinobacter sp. was discovered in this study. Phylogenetic classification for all the phaC genes isolated from uncultured bacteria has revealed that seawater and other environmental resources harbor a great diversity of PhaCs with activities that have not yet been investigated. Functional evaluation of these in silico-based PhaCs via genome walking has provided new insights into the polymerizing ability of these enzymes.
\end{abstract}

Keywords: Japan seawater, Polyhydroxyalkanoate (PHA), PHA synthase (PhaC), Whole genome amplification (WGA), Genome walking, Marinobacter

\section{Background}

The Japanese ocean is special because of its ranges of latitude and depth. There are many deep-sea trenches and troughs with approximately $80 \%$ of the seafloor lying below $1000 \mathrm{~m}$. The Japan Trench and Nankai Trough are part of the Pacific Ring of Fire where submarine volcanoes

\footnotetext{
*Correspondence: ksudesh@usm.my; minami@riken.jp

${ }^{2}$ Ecobiomaterial Research Laboratory, School of Biological Sciences, Universiti Sains Malaysia, 11800 Gelugor, Penang, Malaysia

'Synthetic Genomics Research Team, Biomass Engineering Program Cooperation Division, RIKEN Center for Sustainable Resource Science (CSRS), Yokohama, Kanagawa 230-0045, Japan

Full list of author information is available at the end of the article
}

and hydrothermal vents are present along the tectonic plates. Two major sea surface currents, cold (Oyashio) from the North and warm (Kuroshio) from the South, flow along the Pacific coast of Japan and meet at the Japan Trench. These factors have contributed to the high diversity of marine species in the region [1]. Marine environments include some of the most diverse sets of microorganisms that have important roles in both biogeochemical cycles and ecosystems [2-4].

Polyhydroxyalkanoate (PHA) is naturally produced by many bacteria and some archaea under stressful or 
unbalanced nutritional conditions when there is an excessive supply of carbon sources [5-7]. This polymer can be used for bio-based and biodegradable plastic. Three major enzymes that are involved in the PHA biosynthetic pathway are $\beta$-ketothiolase (PhaA), NADP-dependent acetoacetyl-CoA reductase (PhaB) and polyhydroxyalkanoate synthase (PhaC). PhaC (EC 2.3.1-), the key enzyme involved in the polymerization process, determines the types of monomers ( $R$-hydroxyacyl-CoAs) incorporated into the PHA polymer chain based on the enzyme's substrate specificity [8-10].

PhaCs are categorized into four classes according to the subunits present and the substrate specificity [9]. Most of the PHA producers make Class I and II PhaCs. Primers targeting different classes of PhaC are available, e.g. general primers for Class I and II [11,12], Class II specific [13,14], Class III for Haloarchaea [15] and Desulfococcus [16], and Class IV for Bacillus spp. [17]. Although all the PhaCs share some common amino acid residues, it is not yet possible to amplify all four classes of $\mathrm{PhaC}$ with a single primer set. The general primers targeted to Class I and II PhaCs cover a wider range of bacterial genera (at least nine different genera) compared to the specific primer sets that target Class III and IV PhaCs.

To the best of our knowledge, this is the first attempt to identify $\mathrm{PhaC}$ diversity from seawater from different depths using a culture-independent approach. In this study, we decided to use the Class I and II general primers [12] to identify novel PhaCs from seawater. Seawater samples as deep as $3000 \mathrm{~m}$ and $5000 \mathrm{~m}$ were collected from the Nankai Trough and Japan Trench, respectively. This study also serves as the first trial using a whole genome amplification and genome walking approach [18] to determine the complete coding DNA sequence (CDS) of unstudied phaC genes followed by evaluation of $\mathrm{PhaC}$ activity for PHA production in Cupriavidus necator $\mathrm{PHB}^{-4}$ (a PHB-negative mutant strain).

\section{Results}

PHA synthase fragments from whole genome amplified seawater DNA

A total of 76 partial putative phaC clones were obtained from the seawater whole genome amplified (WGA) DNA. Twenty-one clones did not show any similarity with PhaCs in the GenBank protein sequences database using the BLASTX program and were excluded from subsequent analysis. The remaining 55 clones that contained the putative conserved domain superfamilies "PhaC_N" were classified into 20 different genetic groups (GGs) based on a cut off of $90 \%$ nucleotide sequence similarity. Seven clones containing an internal stop codon 'TAG' within the coding region of the putative PhaC were hypothesized to be pseudogenes. Three GGs (I-GG5, I-
GG13 and II-GGb) were comprised solely of these pseudogenes.

Eighteen I-GGs and two II-GGs PhaCs were detected using the PhaC degenerate primer sets G-D and G-1R. These GGs were designated as "PhaC-I" or "PhaC-II" depending on the similarity with Class I or Class II PhaCs, respectively. This grouping generated similar results to the neighbor-joining phylogenetic tree (Additional file 1: Figure S2), where clones designated as the same "GG" were closely clustered in the same branch. For all the GGs, a putative lipase box (G-X-[S/C]-X-G) was identified from a MUSCLE alignment (Additional file 2: Figure S1). The only exceptions were I-GG12 and IGG17 in which the first amino acid residue 'glycine (G)' in the lipase box motif was replaced by 'serine (S)' and 'alanine (A)', respectively. In addition, three amino acid residues, serine (S), aspartic acid (D) and tryptophan (W), that were conserved in the previously reported multiple sequence alignment of $\mathrm{PhaC}$ [9] were also present in all GGs.

The protein sequence identities of 55 partial PhaC fragments against the GenBank protein sequences database ranged from 57\% to 99\% (Additional file 3: Table S3). There were five putative PhaC-GGs with very high identity matches (>90\%): I-GG16, II-GGa and II-GGb to known PHA producers from the genera Chromobacterium (Class I) and Pseudomonas (Class II), and I-GG17 and IGG18 to unknown PHA producers from gamma proteobacterium HIMB30 and genus Marinobacter, respectively (Figure 1).

Another four putative PhaC-GGs (I-GG5, I-GG13, I-GG14 and I-GG15) with BLASTX identity matches between 71-83\% showed relatively close phylogenetic clustering with the PhaCs from the genera Rhodospirillum, Acetobacteraceae bacterium, Oceanibaculum and Oceanicaulis, respectively. The genus Rhodospirillum has a known PHA producer, Rhodospirillum rubrum [19], while the other genera include phaC genes annotated from the bacterial whole genome sequence (WGS). The remaining 11 putative PhaC-GGs (I-GG1 to GG4 and I-GG6 to GG12) that showed relatively distinct phylogenetic clusters when compared with the PhaC from cultured bacteria are believed to derive from yet uncultured bacteria.

\section{PhaC from culture-independent studies}

Further comparison was carried out by compiling our phaC fragments and all predicted phaC fragments including unpublished data from various cultureindependent studies (Figure 1) (Additional file 4: Table S4). Since our phaC fragments belonged to Class I and II, we only compared these two classes. In total, there are 301 putative phaC genes in the GenBank nucleotide sequences database (as of 22nd April 2014). 


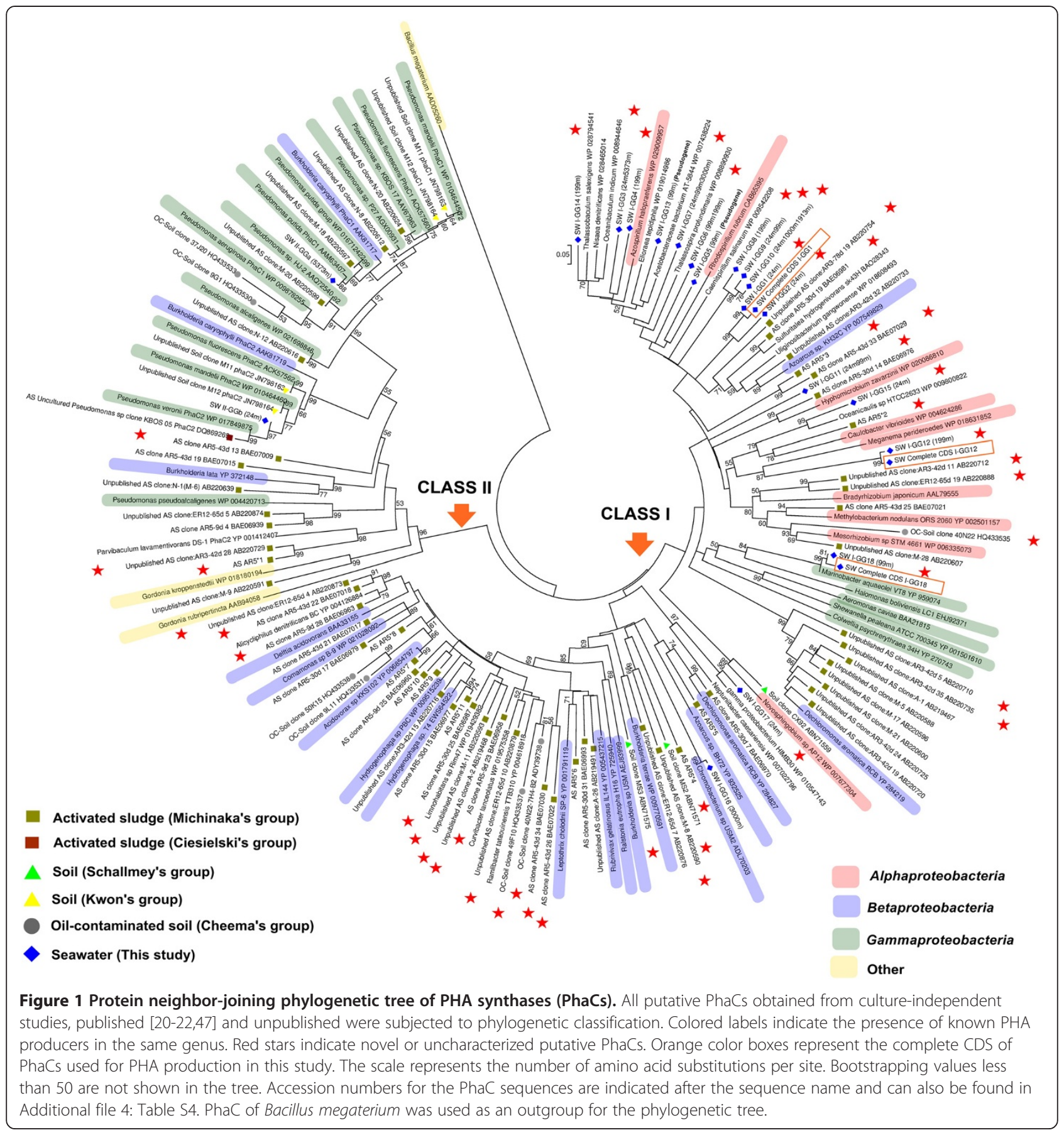

Putative phaC genes with nucleotide sequence similarity $>90 \%$ were assigned to the same genetic group.

The study on activated-sludge PhaC diversity [20] generated the largest number of partial phaC sequences with most of them belonging to Class I PhaC of Betaproteobacteria, followed by Class I PhaC of Alphaproteobacteria and Class II PhaC of Gammaproteobacteria. The same dominant group, Class I PhaC of Betaproteobacteria, was found in oil-contaminated soil DNA [21], followed by Class II PhaC of Gammaproteobacteria and Class I PhaC of Alphaproteobacteria. In contrast, Class I PhaC of Alphaproteobacteria was more dominant in the seawater DNA, followed by Class I PhaC of Betaproteobacteria, and Class I and II PhaC of Gammaproteobacteria. On the other hand, three complete CDSs of Class I PhaC of Alphaproteobacteria and Betaproteobacteria were isolated from the soil DNA genomic library [22]. Our seawater samples contained a higher proportion (15 out of 20 GGs) of novel or uncharacterized phaC fragments compared with samples from other environments. 


\section{Isolation of complete coding region of phaC gene}

The complete coding regions of three Class I GGs were determined via in silico assembly of DNA fragments obtained by inverse affinity nested PCR (IAN-PCR) (Figure 2). These I-GGs were selected based on their low (I-GG12 =57\%), medium (I-GG1 = 68-73\%) and high $(\mathrm{I}-\mathrm{GG} 18=99 \%)$ partial protein sequence identities with PhaC from the unknown PHA producers deposited in the GenBank protein sequences database (Additional file 3: Table S3). The length of the I-GG1 genome walking DNA fragment was $3878 \mathrm{bp}$. The downstream region showed close protein similarity with MFS permease (47\% identity) followed by peroxidase ( $61 \%$ identity). The upstream region could not be determined due to the presence of an EcoRI restriction digestion site. This could be an incomplete CDS of a protein with approximately 8 to 14 amino acid residues missing at the $\mathrm{N}$-terminal end based on multiple sequence alignment analysis (Additional file 5: Figure S3). The length of the IGG12 genome walking DNA fragment was $3157 \mathrm{bp}$. The downstream region showed close protein similarity with the TetR family transcriptional regulator (58\% identity). The length of the I-GG18 genome walking DNA fragment was 3885 bp (including the predicted region). We were only able to obtain the upstream region of the PhaC based on BLASTN similarity searches. Nonetheless, there was a high identity match (>95\%) with PHA synthase and the upstream region (phasin and sodium/sulfate symporter) of Marinobacter hydrocarbonoclasticus ATCC 49840. Therefore, a reverse primer was designed based on the hypothetical protein located downstream of the $\mathrm{PhaC}$ of Marinobacter hydrocarbonoclasticus ATCC 49840.

The complete CDSs of I-GG1, I-GG12 and I-GG18 were confirmed by DNA sequencing and their closest PhaC matches from BLASTX analysis were Oceanibaculum indicum (65\%), Tistrella mobilis (50\%) and Marinobacter sp. C1S70 (97\%), respectively (Table 1). High nucleotide sequence similarities (>96\%) were observed between the partial phaC genes and their corresponding complete CDSs obtained by the genome walking method. The primary structure of the three putative complete PhaC CDSs indicated the presence of a lipase box motif. In addition, eight highly conserved amino acid residues were also present in these putative PhaCs (Additional file 5: Figure S3) based on observations reported in a previous study [23].

\section{A) I-GG1, 3878 bp}

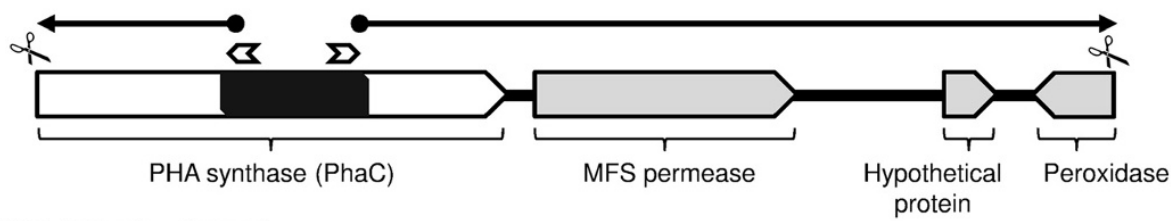

B) I-GG12, 3157 bp

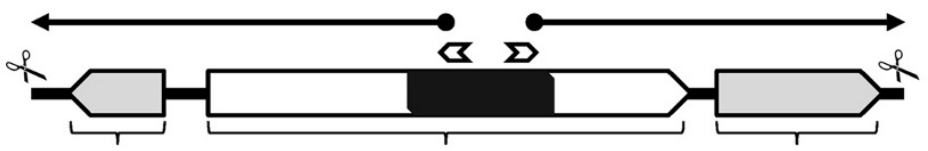

Hypothetical protein $\quad$ PHA synthase (PhaC)

TetR family transcriptional regulator

\section{C) I-GG18, 3885 bp}

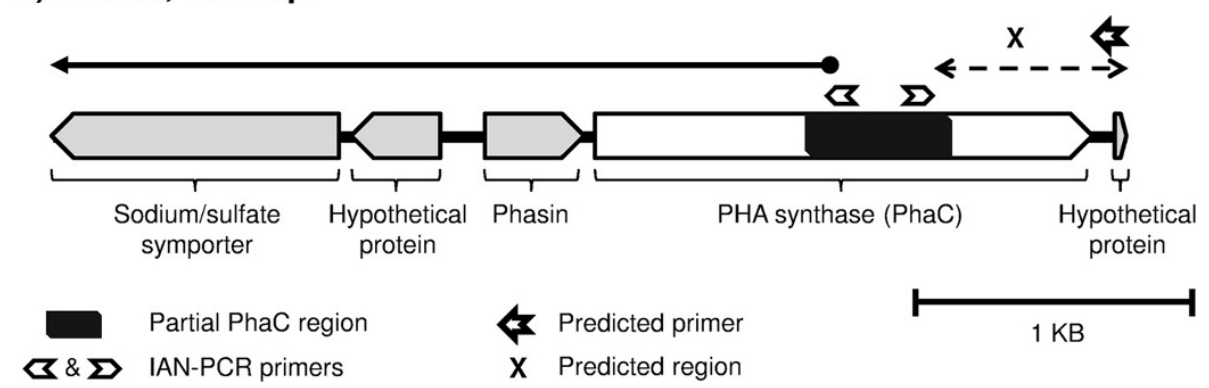

Figure $\mathbf{2}$ Schematic diagram for the DNA fragments obtained by genome walking. Major facilitator superfamily (MFS) permease is a membrane transporter. TetR is a tetracycline repressor protein. Phasin is a PHA granule-associated protein. The bold arrow lines indicate the DNA fragment amplified by IAN-PCR. The scissors indicate the restriction digestion site for EcoRI. For the DNA fragment I-GG18, the EcoRI digestion site could not be identified. The downstream region of the I-GG18 PHA synthase was determined via PCR amplification using a predicted primer based on the whole genome sequence (WGS) of Marinobacter hydrocarbonoclasticus strain ATCC 49840. 
Table 1 Closest organism matches of PHA synthase for the complete CDS phaC genes

\begin{tabular}{llllll}
\hline Genetic group & Nucleotide length (bp) & Amino acid length (aa) & Closest organism match $^{\text {a }}$ & Identity (\%) & Accession no. \\
\hline I-GG18 & 1800 & 599 & Marinobacter sp. C1S70 & 97 & WP_022991790 \\
I-GG1 & 1701 & 566 & Oceanibaculum indicum & 65 & WP_008944646 \\
I-GG12 & 1746 & 581 & Tistrella mobilis & 50 & WP_0147455461 \\
\hline
\end{tabular}

${ }^{a}$ BLASTX against the GenBank non-redundant protein sequences database (nr), date: 21st September 2014.

\section{PHA polymerizing activity in C. necator $\mathrm{PHB}^{-4}$}

The complete CDSs of three phaC sequences were subjected to functional analysis of PHA production in $C$. necator $\mathrm{PHB}^{-} 4$, which is deficient in endogenous phaC function. Of the three phaCs, only I-GG18 was able to produce $60 \mathrm{wt} \%$ of $\mathrm{P}(3 \mathrm{HB})$ (Table 2) under the control of the phaC1 promoter from Cupriavidus necator H16. On the other hand, I-GG18 (without the promoter) did not show any PHA production under the same cultivation conditions.

\section{Discussion}

Unexplored PHA synthases from the Japan Trench and Nankai Trough

The Japan Trench and Nankai Trough have unique environmental features, one of them is their seawater temperature which is influenced by surface currents and depth [1]. PHA producers have been isolated from various marine-associated environments [24,25], however, there are no previous reports on the study of PHA synthase from the Japan Trench and Nankai Trough. A degenerate primer set (G-D and G-1R) targeting Class I and II PhaCs developed by Romo et al. [12] was used in this study. We successfully isolated 76 partial phaC fragments and classified them into 20 GGs (including three PhaC-GGs comprised solely of pseudogenes) for both Class I and II PhaCs from whole genome amplified (WGA) seawater DNA.

Table 2 PHA production of different phaC genes in recombinant $\mathrm{C}$. necator $\mathrm{PHB}^{-} 4^{\mathrm{a}}$

\begin{tabular}{llll}
\hline Sample name & $\begin{array}{l}\text { Dry cell } \\
\text { weight (g/L) }\end{array}$ & $\begin{array}{l}\text { PHA content } \\
\text { (wt \%) }\end{array}$ & $\begin{array}{l}\text { PHA } \\
\text { composition }\end{array}$ \\
\hline $\begin{array}{l}\text { C. necator H16 } \\
\text { (Wild type) }\end{array}$ & $4.1 \pm 0.5$ & $70 \pm 5$ & $\mathrm{P}(3 \mathrm{HB})$ \\
$\begin{array}{l}\text { C. } \text { necator PHB-4 } \\
\text { (PHB-negative mutant) }\end{array}$ & $1.2 \pm 0$ & $\mathrm{n} / \mathrm{d}$ & $\mathrm{n} / \mathrm{d}$ \\
I-GG1 & $0.9 \pm 0$ & $\mathrm{n} / \mathrm{d}$ & $\mathrm{n} / \mathrm{d}$ \\
I-GG12 & $0.9 \pm 0$ & $\mathrm{n} / \mathrm{d}$ & $\mathrm{n} / \mathrm{d}$ \\
I-GG18 & $2.6 \pm 0.1$ & $60 \pm 8$ & $\mathrm{P}(3 \mathrm{HB})$ \\
I-GG18 & & $\mathrm{n} / \mathrm{d}$ & $\mathrm{n} / \mathrm{d}$
\end{tabular}

${ }^{\mathrm{a} C e l l s}$ were cultivated in $\mathrm{MM}$ medium at $30^{\circ} \mathrm{C}, 200 \mathrm{rpm}$ for 48 hours with $20 \mathrm{gL}^{-1}$ of fructose as the sole carbon source. $\mathrm{n} / \mathrm{d}=$ not detected.
In this study, 11 putative PhaC-GGs showed relatively low sequence identity $(\leq 80 \%)$ and distinct phylogenetic lineage with the PhaCs from known PHA producers. We hypothesized that these PhaC-GGs are derived from yet uncultured bacteria. In addition, four putative PhaCGGs that showed high sequence similarity (81-99\%) with annotated PhaCs from unknown PHA producers (Thalassobaculum salexigens, Oceanicaulis sp., gamma proteobacterium HIMB30 and Marinobacter sp.). In total, 15 new or uncharacterized putative PhaC-GGs (excluding pseudogenes) were discovered from the WGA seawater DNA examined in this study.

Novel bacterial species have been discovered from the deep sea of both the Japan Trench and the Nankai Trough [26-28]. Indeed, the microbial biosphere in deep-sea environments is surprisingly diverse [2,29]. To date, the occurrence of PHA producers in deep-sea water that have been reported include Moritella sp. $(8683 \mathrm{~m})$ and Shewanella sp. (5110 m) from the Pacific Ocean [30], Halomonas profundus (2291 m) from the Mid Atlantic ridge [31] and Pseudoaltermonas sp. (1855 m) from Bohai Sea sediment [32]. Four sites located between the depths of $1000 \mathrm{~m}$ and $5373 \mathrm{~m}$ were sampled in this study. A total of five putative PhaCGGs (I-GG3, I-GG7, I-GG10, I-GG16 and II-GGa) were identified from these deep-sea regions. Two putative PhaC-GGs obtained from $3000 \mathrm{~m}$ and $5373 \mathrm{~m}$ had very high sequence identity to known PHA producers from Chromobacterium sp. (98\%) and Pseudomonas sp. (99\%), respectively. We conclude that the occurrence of these clones was not due to experimental contamination because of the presence of non-random nucleotide mismatches. Most of these nucleotide mismatches occurred at third codon positions encoding for the same amino acids or functionally similar amino acid side groups. Neither of these genera has been reported previously to be deep-sea PHA producers. Nevertheless, several Pseudomonas sp. have been isolated from deep-sea environments [33-35], and isolates from the genus Chromobacterium have been found in the Southern Ocean below $200 \mathrm{~m}$ [36]. The remaining three putative PhaC-GGs were found to be conserved in water columns from different depths with clones detected in both shallow $(24 \mathrm{~m})$ and deep seawater $(1913 \mathrm{~m}, 3000 \mathrm{~m}$ and $5373 \mathrm{~m})$. We speculate that these three are derived from non-cultured bacteria due to 
their distinct phylogenetic lineage with known PHA producers.

We also attempted to examine the functionality of three uncharacterized putative PhaC-GGs from the WGA seawater DNA. Complete protein coding sequences are required for this purpose, thus a genome walking approach (IAN-PCR) was employed to obtain the complete CDSs. Of the three complete putative PhaC CDSs, only I-GG18 with high sequence identity to Marinobacter sp. showed $60 \mathrm{wt} \%$ of $\mathrm{P}(3 \mathrm{HB})$ accumulation in recombinant $C$. necator $\mathrm{PHB}^{-}$. The reason for the inability of recombinant $C$. necator $\mathrm{PHB}^{-} 4$ harboring either I-GG1 or I-GG12 to produce PHA is unknown. The expression of the phaC gene alone may not form an active protein in the surrogate host and it may require some other factors to form an active enzyme [37]. Among the three genome walking DNA fragments, only I-GG18 had the phaC clustered with other PHA metabolism related genes, i.e., phasin (phaP), a PHA granule-associated protein. It is not unusual because it is known that in some bacteria the phaC is not present in the same operon with phaA and phaB [38].

To the best of our knowledge, this is the first phaC gene from the genus of Marinobacter that shows functional activity in a heterologous expression host. Bacteria from this genus have been discovered in various habitats and at all depths in the oceans [39]. Some species of bacteria from the genus Marinobacter have been shown to display the ability to degrade hydrocarbons [40-42] and PHA polymers [43]. Very recently, this genus was suspected to be one of the PHA producers [44], but so far no studies have been published confirming PHA production from pure cultures of Marinobacter sp. In this study, we used a nitrogen-limiting medium, mineral salts medium (MM) instead of rich nutrient medium such as LB and NR to promote the accumulation of PHA in the recombinant $C$. necator $\mathrm{PHB}^{-} 4$. This strain required nutrient-limiting conditions such as nitrogen, phosphorus, magnesium, sulphur or oxygen but at the same time with the supply of excess carbon source to initiate PHA biosynthesis [45,46].

\section{New source of PhaC from culture-independent studies}

In this study, we have compiled the phaC sequences obtained from culture-independent studies [20-22,47] and compared their relationship with PhaCs from known PHA producers based on the phylogenetic tree. Bacterial genera with known PHA producers have been summarized by Verlinden et al. [10] and Koller et al. [44,48]. Interestingly, almost half of the $\mathrm{PhaC}$ sequences from culture-independent resources have not been examined for PHA productivity. A noticeable difference is the prevalence of Class I PhaCs of Alphaproteobacteria in seawater DNA with a higher proportion of uncharacterized PhaCs compared with other environmental DNA (activated sludges, soils and oil-contaminated soil) where the Class I PhaCs of Betaproteobacteria is the dominant group. This could be explained by the fact that Alphaproteobacteria is one of the most dominant bacterial groups found in pelagic seawater realms $[3,4,29]$.

We can foresee that the number of uncharacterized PhaCs will increase in the near future due to the popularity of culture-independent approaches and bacterial whole genome sequencing. However, cautious interpretation is needed due to the existence of gene paralogs $[49,50]$ where some bacteria harbor more than one copy of the phaC gene in their genome, such as in C. necator, Bradyrhizobium japonicum, R. rubrum [51-53]. In some cases, these paralogs show low sequence similarity or even belong to different $\mathrm{PhaC}$ classes $[37,53]$. Therefore, further evaluation of $\mathrm{PhaC}$ activity through either in vitro or in vivo approaches will be required, especially for PhaCs retrieved from culture-independent studies.

\section{Conclusions}

A new functional PhaC that has high identity to that of Marinobacter sp. has been discovered and PHA accumulation was observed in recombinant $C$. necator $\mathrm{PHB}^{-} 4$. Further studies are currently ongoing to characterize the full potential of this newly identified PHA synthase. Seawater and other environmental resources harbor a great diversity of phaC genes with unexplored PhaC activity. Functional evaluation of these in silico-based PhaCs via genome walking has provided new insights into the polymerizing ability of the enzyme from rarely cultured microorganisms.

\section{Methods}

\section{Seawater sampling}

The SHINKAI 6500 (JAMSTEC, Japan), a manned research submersible able to dive to a depth of 6500 meters and R/V Tansei maru (AORI, University of Tokyo/JAMSTEC) were used to collect the seawater samples. The samples were taken between August and October 2011 from three locations in the North Pacific Ocean around the Japan Trench and Nankai Trough at depths ranging from $24 \mathrm{~m}$ to $5373 \mathrm{~m}$ (Figure 3 and Table 3). The samples were immediately stored at $-80^{\circ} \mathrm{C}$.

\section{Total DNA extraction and whole genome amplification (WGA)}

Seven seawater samples were selected for this work. Approximately $900 \mathrm{~mL}$ of each sample was defrosted and filtered through $0.22 \mu \mathrm{m}$ pore-sized Sterivex-GP cartridge filters (Millipore, USA) [54]. After filtering, the cartridges were opened and the filter membranes were carefully removed with sterilized forceps and transferred into Lysing 


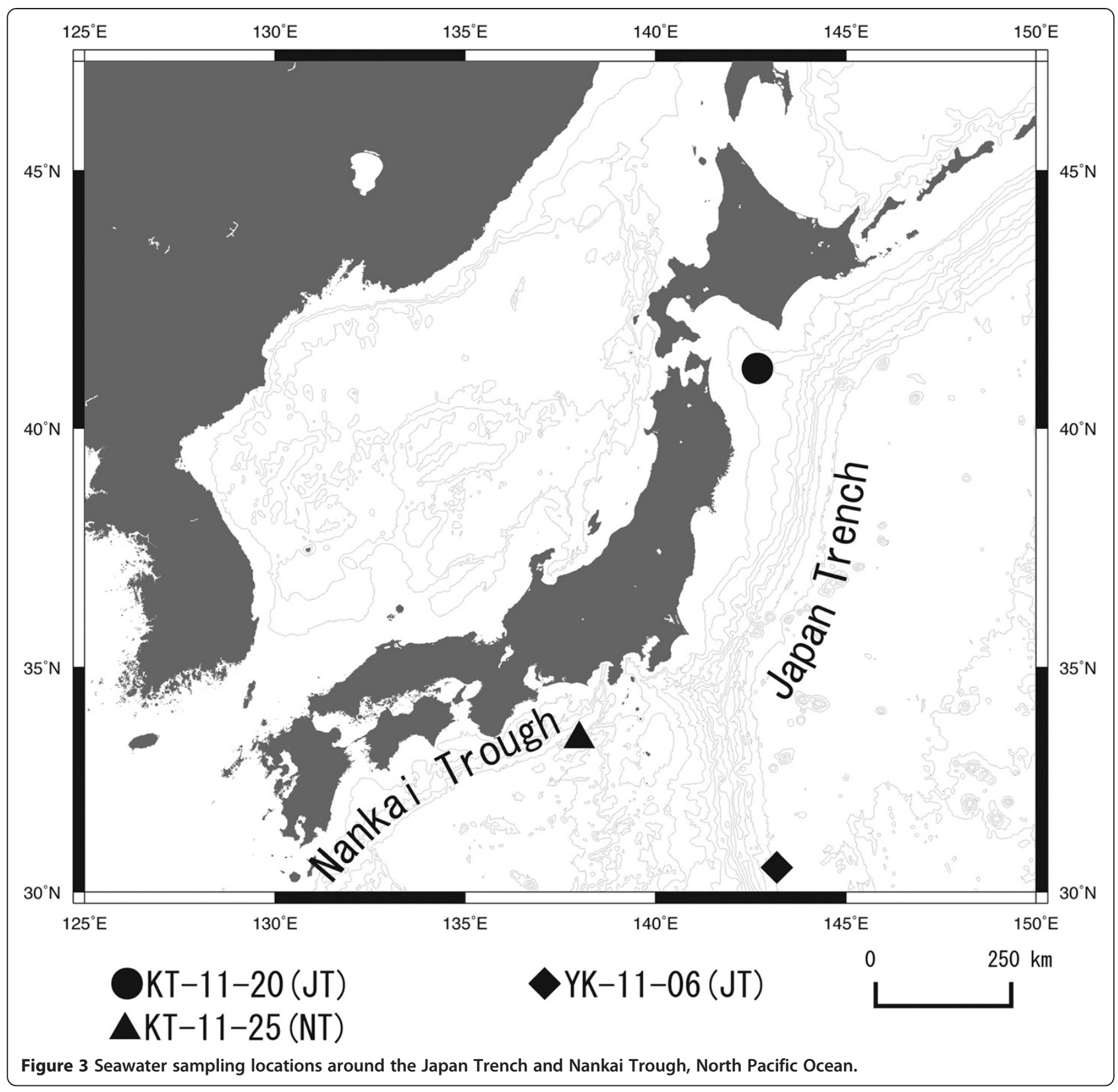

Matrix E tubes, which come with the FastDNA ${ }^{\mathrm{mm}} 2 \mathrm{~mL}$ SPIN Kit for Soil (MP Biomedicals, USA). All of the proceeding steps were carried out under aseptic conditions. Total DNA extraction was carried out according to the manufacturer's protocol with slight modifications including the DNA extraction buffer composition, the addition of lysozyme and Proteinase $\mathrm{K}$ treatments, and a hot-lysis incubation at $65^{\circ} \mathrm{C}$ as described in Zhou et al. [55]. Whole genome amplification (WGA) was performed using the REPLI-g Mini Kit (QIAGEN, Germany) to increase the amounts of DNA to sufficient levels $(>1 \mu \mathrm{g})$ for subsequent experimental analyses.

\section{Screening of PHA synthase (phaC) genes from seawater WGA DNA}

Degenerate primers G-D and G-1R (Additional file 6: Table S1) specifically targeting Class I and II PHA synthases [12] were used to amplify the phaC, phaC1 and phaC2 genes from the WGA seawater DNA. The PCRs contained 1× Ex Taq buffer, $1.5 \mathrm{mM} \mathrm{MgCl}_{2}, 200 \mu \mathrm{M}$ dNTPs, $0.25 \mu \mathrm{M}$ of each primer, $1 \%$ DMSO and $1 \mathrm{U}$ of Ex Taq (TaKaRa, Japan). The PCR conditions were as follows: $94^{\circ} \mathrm{C}$ for $3 \mathrm{~min}$; 30 cycles of $94^{\circ} \mathrm{C}$ for $30 \mathrm{~s}, 55^{\circ} \mathrm{C}$ for $30 \mathrm{~s}$, and $72^{\circ} \mathrm{C}$ for $50 \mathrm{~s}$; a final step at $72^{\circ} \mathrm{C}$ for $7 \mathrm{~min}$. PCR products were run on an agarose gel and those 
Table 3 GPS coordinates and description of the sampling sites

\begin{tabular}{|c|c|c|c|c|}
\hline $\begin{array}{l}\text { Sampling } \\
\text { site name }\end{array}$ & $\begin{array}{l}\text { Cruise } \\
\text { name }^{a}\end{array}$ & $\begin{array}{l}\text { GPS } \\
\text { coordinates }\end{array}$ & $\begin{array}{l}\text { Depth } \\
\text { (meters) }\end{array}$ & $\begin{array}{l}\text { Temperature } \\
\left({ }^{\circ} \mathrm{C}\right)\end{array}$ \\
\hline \multirow[t]{2}{*}{10} & KT-11-20 (JT) & $41^{\circ} 14.4879^{\prime} \mathrm{N}$ & 24 & 17.9 \\
\hline & & $142^{\circ} 59.4645^{\prime} \mathrm{E}$ & & \\
\hline \multirow[t]{2}{*}{7} & KT-11-20 (JT) & $41^{\circ} 14.4879^{\prime} \mathrm{N}$ & 99 & 13.3 \\
\hline & & $142^{\circ} 59.4645^{\prime} \mathrm{E}$ & & \\
\hline \multirow[t]{2}{*}{5} & KT-11-20 (JT) & $41^{\circ} 14.4879^{\prime} \mathrm{N}$ & 199 & 4.6 \\
\hline & & $142^{\circ} 59.4645^{\prime} \mathrm{E}$ & & \\
\hline \multirow[t]{2}{*}{2} & KT-11-20 (JT) & $41^{\circ} 14.4879^{\prime} \mathrm{N}$ & 1000 & 2.9 \\
\hline & & $142^{\circ} 59.4645^{\prime} E$ & & \\
\hline \multirow[t]{2}{*}{1} & KT-11-20 (JT) & $41^{\circ} 14.4879^{\prime} \mathrm{N}$ & 1913 & 2.0 \\
\hline & & $142^{\circ} 59.4645^{\prime} \mathrm{E}$ & & \\
\hline \multirow[t]{2}{*}{3000} & KT-11-25 (NT) & $33^{\circ} 4.999^{\prime} \mathrm{N}$ & 3000 & 1.6 \\
\hline & & $137^{\circ} 36.992^{\prime} E$ & & \\
\hline \multirow[t]{2}{*}{ YK } & YK-11-06 (JT) & $30^{\circ} 8.9596^{\prime} \mathrm{N}$ & 5373 & 1.5 \\
\hline & & $143^{\circ} 34.9867^{\prime} E$ & & \\
\hline
\end{tabular}

aJ = Japan Trench; NT = Nankai Trough.

within the range of 500 to $600 \mathrm{bp}$ were excised from the gel, purified, and inserted into the $\mathrm{pCR}^{\circ} 4-\mathrm{TOPO}^{\circ}$ vector (Invitrogen, USA). The vectors were transformed into E. coli DH5 $\alpha$ (TaKaRa, Japan) and selected on Lysogeny-

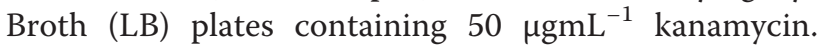
Plasmids from the positive clones were isolated using PowerPrep $^{\mathrm{Tm}}$ Express Plasmid Purification Kits (ORIGEN, USA) and DNA sequencing was carried out at the RIKEN Center for Sustainable Resource Science (CSRS), Yokohama, Japan.

\section{Sequence analyses}

The MegAlign tool (DNASTAR, USA) was used to calculate nucleotide sequence similarity. Clones showing $\geq 90 \%$ identity in their nucleotide sequence were categorized as part of the same genetic group. Sequence similarity searches were conducted using BLASTX 2.2.30 against the GenBank non-redundant protein sequences database [56]. The ExPASy translation tool [57] was used to translate and predict the correct reading frames for the nucleotide sequences. Partial PhaC sequences were aligned using the MUSCLE algorithm [58] of the BioEdit program [59]. Protein sequences were also checked for the presence of the conserved catalytic lipase-box (G-X[S/C]-X-G) [9]. Protein neighbor-joining (NJ) phylogenetic trees were constructed using MEGA5 [60] with MUSCLE alignment and 1000 bootstrap tests.

\section{Genome walking with IAN-PCR}

Genome walking with inverse affinity nested PCR (IANPCR) was carried out to obtain the full-length phaC
DNA sequences [61]. WGA seawater DNA was digested with FastDigest EcoRI (Fermentas, Lithuania) and selfligated using a DNA Ligation Kit Ver1.2 (TaKaRa, Japan). For each genetic group, two sets of primers (for two rounds of amplification) (Additional file 6: Table S1) were designed based on the partial phaC sequences obtained in the previous step. The first round of amplification (inverse affinity PCR) included a 5 '-biotinylated primer that enabled the product to be purified using the KiloBase Binder Kit (Invitrogen, USA) and serve as a template for the second round of amplification (nested PCR). DNA sequences were determined by performing the same cloning and sequencing steps described in the previous section. Full-length phaC sequences were predicted in silico by assembling the genome walking DNA fragments using the SeqMan tool (DNASTAR, USA).

\section{Nucleotides sequence accession numbers}

The nucleotide sequences were submitted to the GenBank nucleotide database. Partial phaC sequences were assigned accession numbers [GenBank: KF911019-KF911073] as were the complete coding sequences (CDS) of the phaC genes [GenBank: KF911074-KF911076].

\section{Heterologous expression of PHA synthases (phaC) in \\ C. necator $\mathrm{PHB}^{-} 4$}

The ribosome binding sequence (RBS) upstream of the start codon for each phaC gene was optimized for $C$. necator via the RBS calculator [62]. The gene constructs were assembled in the following order with appropriate restriction sites (Additional file 6: Table S1): phaC1 promoter from C. necator, optimized RBS, and complete CDS of the phaC genes. After restriction digestion, the gene constructs were inserted into plasmid pBBR1MCS2 [63] in reverse orientation to the lac promoter to ensure that expression was solely controlled by the $C$. necator phaC1 promoter. Bacterial conjugation of $C$. necator $\mathrm{PHB}^{-4}$ with E. coli S17-1 [64] harboring a broad host range vector (pBBR1MCS-2 derivatives) was conducted as described by Friedrich et al. [65]. The presence of the recombinant PHA synthase in recombinant $C$. necator $\mathrm{PHB}^{-} 4$ was confirmed with direct PCR on the bacterial DNA. Wild-type $C$. necator $\mathrm{H} 16$ and PHB-negative mutant $C$. necator $\mathrm{PHB}^{-} 4$ were used as the positive and negative controls for PHA production, respectively (Additional file 7: Table S2). All bacterial strains were pre-cultured at $30^{\circ} \mathrm{C}$, $200 \mathrm{rpm}$ for $6 \mathrm{~h}$ in $50 \mathrm{~mL}$ of Nutrient Rich (NR) medium (300 $\mathrm{gmL}^{-1}$ kanamycin). After culturing, 3\% (v/v) of the inoculum was transferred into $50 \mathrm{~mL}$ of mineral salts medium (MM) (300 $\mathrm{ggmL}^{-1}$ kanamycin) with $20 \mathrm{gL}^{-1}$ of fructose added as the sole carbon source, and incubated at $30^{\circ} \mathrm{C}$, at $200 \mathrm{rpm}$ for $48 \mathrm{~h}$. 


\section{PHA content quantification}

The cells were harvested by centrifugation $(8,000 \mathrm{~g}$ for $10 \mathrm{~min}$ ), washed once with distilled water and kept at $-20^{\circ} \mathrm{C}$ for $24 \mathrm{~h}$ before lyophilization. The dry cell weight of each culture was gravimetrically determined and approximately $20 \mathrm{mg}$ of lyophilized cells were subjected to methanolysis in the presence of $15 \%(\mathrm{v} / \mathrm{v})$ sulfuric acid and $85 \%(\mathrm{v} / \mathrm{v})$ methanol at $100^{\circ} \mathrm{C}$ for $140 \mathrm{~min}$ [66]. The PHA content was determined by gas chromatography (GC) using the Shimadzu GC-2010 system equipped with column SPB-1 (Supelco, USA). The column temperature was initiated at $70^{\circ} \mathrm{C}$ and then increased to $280^{\circ} \mathrm{C}$ in a continuous step of $10^{\circ} \mathrm{C} / \mathrm{min}$. The PHA content and composition were quantified with caprylic acid methyl ester as an internal standard.

\section{Additional files}

Additional file 1: Figure S2. Protein neighbor-joining phylogenetic tree of PHA synthases obtained from WGA seawater DNA. Solid diamonds indicate the consensus $\mathrm{PhaC}$ sequence within the same genetic group (nucleotide sequence identity $>90 \%$ ). White diamonds indicate PhaC sequences with complete CDSs. The scale represents the number of amino acid substitutions per site. Bootstrapping values less than 50 are not shown in the tree.

Additional file 2: Figure S1. Multiple sequence alignment of the partial PhaC proteins obtained from WGA seawater DNA. A MSA was created with Class I and II PhaCs from known PHA producers using MUSCLE. There are three PhaC genetic groups comprised solely of pseudogenes. The location of the putative lipase box (G-X-[S/C]-X-G-G) is outlined. Dark colored columns represent completely conserved amino acids. Abbreviation: A. = Aeromonas; B. = Bradyrhizobium; C. = Cupriavidus; P. $=$ Pseudomonas.

Additional file 3: Table S3. Genetic groups and closest organism matches of PHA synthases for the partial phaC genes.

Additional file 4: Table S4. Accession numbers for all the PHA synthases used in the protein neighbor-joining phylogenetic tree.

Additional file 5: Figure S3. Multiple sequence alignment of three putative complete PhaC CDSs with known functional PHA synthases. A MSA was created with Class I and II PhaCs from known PHA producers using MUSCLE. The location of the putative lipase box (G-X-[S/C]-X-G-G) is outlined. Eight highly conserved amino acid residues are indicated by arrows. Dark colored columns represent completely conserved amino acids. Abbreviation: A. = Aeromonas; $\mathrm{B} .=$ Bradyrhizobium; C. = Cupriavidus; P. $=$ Pseudomonas.

Additional file 6: Table S1. List of primers used in this study. Additional file 7: Table S2. List of plasmids and strains used in this study.

\section{Competing interests}

The authors declare that they have no competing interests.

\section{Authors' contributions}

CPF carried out the research and wrote the manuscript. CPF, NSL, MM and KS participated in the design of the study. SD and TT provided the seawater samples. TDT, MM and KS were involved in drafting and critical revision of the manuscript. All authors read and approved the final manuscript.

\section{Acknowledgements}

This study was supported by the Biomass Engineering Program (RIKEN) and the Long Term Research Grant Scheme (Universiti Sains Malaysia). We thank the SINKAI 6500 and RN Tansei maru crew and members for their help in sampling the deep-sea water. We are also grateful to Dr. Kovach ME for his kind gift of the PBBR1MCS broad-host-range vector derivatives used in this study. CPF and NSL gratefully acknowledge the MyPhD scholarship from the Ministry of Higher Education Malaysia and the USM fellowship program, respectively. Both CPF and NSL also acknowledge financial support as Short-Term International Program Associates under a collaboration between RIKEN and USM.

\section{Author details}

${ }^{1}$ Synthetic Genomics Research Team, Biomass Engineering Program Cooperation Division, RIKEN Center for Sustainable Resource Science (CSRS), Yokohama, Kanagawa 230-0045, Japan. ${ }^{2}$ Ecobiomaterial Research Laboratory, School of Biological Sciences, Universiti Sains Malaysia, 11800 Gelugor, Penang, Malaysia. ${ }^{3}$ Centre for Chemical Biology, Universiti Sains Malaysia, 11800 Gelugor, Penang, Malaysia. ${ }^{4}$ R\&D Center for Marine Biosciences, Japan Agency for Marine-Earth Science and Technology (JAMSTEC), 2-15 Natsushima-cho, Yokosuka 237-0061, Japan. ${ }^{5}$ Laboratory for Integrated Bioinformatics, Core for Precise Measuring and Modeling, RIKEN Center for Integrative Medical Sciences (IMS), Yokohama, Kanagawa 230-0045, Japan.

Received: 13 October 2014 Accepted: 10 December 2014

Published online: 24 December 2014

\section{References}

1. Fujikura K, Lindsay D, Kitazato H, Nishida S, Shirayama Y: Marine biodiversity in Japanese waters. PLoS One 2010, 5(8):e11836.

2. Sogin ML, Morrison HG, Huber JA, Mark Welch D, Huse SM, Neal PR, Arrieta JM, Herndl GJ: Microbial diversity in the deep sea and the underexplored "rare biosphere". Proc Natl Acad Sci U S A 2006, 103(32):12115-12120.

3. Zinger L, Amaral-Zettler LA, Fuhrman JA, Horner-Devine MC, Huse SM, Welch DBM, Martiny JBH, Sogin M, Boetius A, Ramette A: Global patterns of bacterial beta-diversity in seafloor and seawater ecosystems. PLoS One 2011, 6(9):e24570.

4. Du J, Xiao K, Li L, Ding X, Liu H, Lu Y, Zhou S: Temporal and spatial diversity of bacterial communities in coastal waters of the South china sea. PLoS One 2013, 8(6)::66968.

5. Sudesh K, Abe H, Doi Y: Synthesis, structure and properties of polyhydroxyalkanoates: biological polyesters. Prog Polym Sci 2000 25(10):1503-1555.

6. Koller M, Hesse P, Bona R, Kutschera C, Atlic A, Braunegg G: Potential of various archae- and eubacterial strains as industrial polyhydroxyalkanoate producers from whey. Macromol Biosci 2007, 7(2):218-226.

7. Nomura CT, Taguchi S: PHA synthase engineering toward superbiocatalysts for custom-made biopolymers. App/ Microbiol Biotechnol 2007, 73(5):969-979.

8. Steinbüchel A, Hein S: Biochemical and molecular basis of microbial synthesis of polyhydroxyalkanoates in microorganisms. Adv Biochem Eng Biotechnol 2001, 71:81-123.

9. Rehm BH: Polyester synthases: natural catalysts for plastics. Biochem $J$ 2003, 376(Pt 1):15-33.

10. Verlinden RA, Hill DJ, Kenward MA, Williams CD, Radecka I: Bacterial synthesis of biodegradable polyhydroxyalkanoates. J Appl Microbiol 2007, 102(6):1437-1449.

11. Sheu DS, Wang YT, Lee CY: Rapid detection of polyhydroxyalkanoateaccumulating bacteria isolated from the environment by colony PCR. Microbiology 2000, 146:2019-2025.

12. Romo DMR, Grosso MV, Solano NCM, Castano DM: A most effective method for selecting a broad range of short and medium-chain-length polyhidroxyalcanoate producing microorganisms. Electron J Biotechnol 2007, 10(3):348-357.

13. Solaiman DK, Ashby RD, Foglia TA: Rapid and specific identification of medium-chain-length polyhydroxyalkanoate synthase gene by polymerase chain reaction. Appl Microbiol Biotechnol 2000, 53(6):690-694

14. Zhang G, Hang X, Green P, Ho KP, Chen GQ: PCR cloning of type II polyhydroxyalkanoate biosynthesis genes from two Pseudomonas strains. FEMS Microbiol Lett 2001, 198(2):165-170.

15. Han J, Hou J, Liu H, Cai S, Feng B, Zhou J, Xiang H: Wide distribution among halophilic archaea of a novel polyhydroxyalkanoate synthase subtype with homology to bacterial type III synthases. Appl Environ Microbiol 2010, 76(23):7811-7819. 
16. Hai T, Lange D, Rabus R, Steinbuchel A: Polyhydroxyalkanoate (PHA) accumulation in sulfate-reducing bacteria and identification of a class III PHA synthase (PhaEC) in Desulfococcus multivorans. Appl Environ Microbiol 2004, 70(8):4440-4448.

17. Shamala TR, Chandrashekar A, Vijayendra SV, Kshama L: Identification of polyhydroxyalkanoate (PHA)-producing Bacillus spp. using the polymerase chain reaction (PCR). J Appl Microbiol 2003, 94(3):369-374

18. Kotik M: Novel genes retrieved from environmental DNA by polymerase chain reaction: current genome-walking techniques for future metagenome applications. J Biotechnol 2009, 144(2):75-82.

19. Brandl H, Knee EJ Jr, Fuller RC, Gross RA, Lenz RW: Ability of the phototrophic bacterium Rhodospirillum rubrum to produce various poly (beta-hydroxyalkanoates): potential sources for biodegradable polyesters. Int J Biol Macromol 1989, 11(1):49-55.

20. Michinaka A, Arou J, Onuki M, Satoh H, Mino T: Analysis of polyhydroxyalkanoate $(\mathrm{PHA})$ synthase gene in activated sludge that produces PHA containing 3-hydroxy-2-methylvalerate. Biotechnol Bioeng 2007, 96(5):871-880.

21. Cheema S, Bassas-Galia M, Sarma PM, Lal B, Arias S: Exploiting metagenomic diversity for novel polyhydroxyalkanoate synthases: production of a terpolymer poly(3-hydroxybutyrate-co-3-hydroxyhexanoateco-3-hydroxyoctanoate) with a recombinant Pseudomonas putida strain. Bioresour Technol 2012, 103(1):322-328.

22. Schallmey M, Ly A, Wang C, Meglei G, Voget S, Streit WR, Driscoll BT, Charles TC: Harvesting of novel polyhydroxyalkanaote (PHA) synthase encoding genes from a soil metagenome library using phenotypic screening. FEMS Microbiol Lett 2011, 321(2):150-156.

23. Rehm BH: Biogenesis of microbial polyhydroxyalkanoate granules: a platform technology for the production of tailor-made bioparticles. Curr Issues Mol Biol 2007, 9(1):41-62

24. Chien C-C, Chen C-C, Choi M-H, Kung S-S, Wei Y-H: Production of poly- $\beta$-hydroxybutyrate (PHB) by Vibrio spp. isolated from marine environment. J Biotechnol 2007, 132(3):259-263.

25. Arun A, Arthi R, Shanmugabalaji $V$, Eyini M: Microbial production of poly- $\beta$-hydroxybutyrate by marine microbes isolated from various marine environments. Bioresour Technol 2009, 100(7):2320-2323.

26. Maruyama A, Honda D, Yamamoto H, Kitamura K, Higashihara T: Phylogenetic analysis of psychrophilic bacteria isolated from the Japan Trench, including a description of the deep-sea species Psychrobacter pacificensis sp. nov. Int J Syst Evol Microbiol 2000, 50:835-846.

27. Kormas KA, Smith DC, Edgcomb V, Teske A: Molecular analysis of deep subsurface microbial communities in Nankai Trough sediments (ODP Leg 190, Site 1176). FEMS Microbiol Ecol 2003, 45(2):115-125.

28. Webster G, Parkes RJ, Fry JC, Weightman AJ: Widespread occurrence of a novel division of bacteria identified by $16 \mathrm{~S}$ rRNA gene sequences originally found in deep marine sediments. Appl Environ Microbiol 2004, 70(9):5708-5713.

29. Eloe EA, Fadrosh DW, Novotny M, Zeigler Allen L, Kim M, Lombardo MJ, Yee-Greenbaum J, Yooseph S, Allen EE, Lasken R, Williamson SJ, Bartlett DH: Going deeper: metagenome of a hadopelagic microbial community. PLOS One 2011, 6(5):e20388.

30. Numata K, Morisaki K, Tomizawa S, Ohtani M, Demura T, Miyazaki M, Nogi Y, Deguchi S, Doi Y: Synthesis of poly- and oligo(hydroxyalkanoate)s by deep-sea bacteria, Colwellia spp., Moritella spp., and Shewanella spp. Polym J 2013, 45(10):1094-1100.

31. Simon-Colin C, Raguénès G, Cozien J, Guezennec JG: Halomonas profundus sp. nov., a new PHA-producing bacterium isolated from a deep-sea hydrothermal vent shrimp. J App/ Microbiol 2008, 104(5):1425-1432.

32. Wang $Q$, Zhang $H$, Chen $Q$, Chen $X$, Zhang $Y$, Qi Q: A marine bacterium accumulates polyhydroxyalkanoate consisting of mainly 3hydroxydodecanoate and 3-hydroxydecanoate. World J Microbiol Biotechnol 2010, 26(6):1149-1153.

33. Wang C, Ozuna S, Clark D, Keasling J: A deep-sea hydrothermal vent isolate, Pseudomonas aeruginosa CW961, requires thiosulfate for $\mathrm{Cd}^{2+}$ tolerance and precipitation. Biotechnol Lett 2002, 24(8):637-641.

34. Romanenko LA, Uchino M, Falsen E, Frolova GM, Zhukova NV, Mikhailov W: Pseudomonas pachastrellae sp. nov., isolated from a marine sponge. Int J Syst Evol Microbiol 2005, 55(2):919-924.

35. Ramalingam $V$, Rajaram R, PremKumar C, Santhanam P, Dhinesh $P$, Vinothkumar S, Kaleshkumar K: Biosynthesis of silver nanoparticles from deep sea bacterium Pseudomonas aeruginosa JQ989348 for antimicrobial, antibiofilm, and cytotoxic activity. J Basic Microbiol 2013, 54(9):928-936.

36. Bineesh KK, Sanjeevan VN, Jaleel KUA, Philip R: Distribution of heterotrophic bacterioplankton in the Indian sector of Southern Ocean. J Mar Biol Ass India 2011, 53(2):225-229.

37. Peplinski K, Ehrenreich A, Doring C, Bomeke M, Reinecke F, Hutmacher C, Steinbüchel A: Genome-wide transcriptome analyses of the 'Knallgas' bacterium Ralstonia eutropha $\mathrm{H} 16$ with regard to polyhydroxyalkanoate metabolism. Microbiology 2010, 156(Pt 7):2136-2152.

38. Rehm BHA, Steinbüchel A: Biochemical and genetic analysis of PHA synthases and other proteins required for PHA synthesis. Int JBiol Macromol 1999, 25(1-3):3-19.

39. Singer E, Webb EA, Nelson WC, Heidelberg JF, Ivanova N, Pati A, Edwards KJ: Genomic potential of Marinobacter aquaeolei, a biogeochemical "opportunitroph". Appl Environ Microbiol 2011, 77(8):2763-2771.

40. Gauthier MJ, Lafay B, Christen R, Fernandez L, Acquaviva M, Bonin P, Bertrand JC: Marinobacter hydrocarbonoclasticus gen. nov., sp. nov., a new, extremely halotolerant, hydrocarbon-degrading marine bacterium. Int J Syst Bacteriol 1992, 42(4):568-576.

41. Huu NB, Denner EB, Ha DT, Wanner G, Stan-Lotter H: Marinobacter aquaeolei sp. nov., a halophilic bacterium isolated from a Vietnamese oil-producing well. Int J Syst Bacteriol 1999, 49 Pt 2:367-375.

42. Gao W, Cui Z, Li Q, Xu G, Jia X, Zheng L: Marinobacter nanhaiticus sp. nov., polycyclic aromatic hydrocarbon-degrading bacterium isolated from the sediment of the South China Sea. Antonie Van Leeuwenhoek 2013, 103(3):485-491.

43. Kasuya K, Mitomo H, Nakahara M, Akiba A, Kudo T, Doi Y: Identification of a marine benthic $\mathrm{P}(3 \mathrm{HB})$-degrading bacterium isolate and characterization of its $\mathrm{P}(3 \mathrm{HB})$ depolymerase. Biomacromolecules 2000, 1(2):194-201.

44. Koller M, Salerno A, Braunegg G: Polyhydroxyalkanoates: basics, production and applications of microbial biopolyesters. In: Kabasci S, Stevens C, editors. Bio-based plastics: materials and applications. New York: Wiley; 2013. p. 137-170.

45. Anderson AJ, Dawes EA: Occurrence, metabolism, metabolic role, and industrial uses of bacterial polyhydroxyalkanoates. Microbiol Rev 1990, 54(4):450-472

46. Khanna S, Srivastava AK: Recent advances in microbial polyhydroxyalkanoates. Process Biochem 2005, 40(2):607-619.

47. Ciesielski S, Pokoj T, Klimiuk E: Molecular insight into activated sludge producing polyhydroxyalkanoates under aerobic-anaerobic conditions. J Ind Microbiol Biotechnol 2008, 35(8):805-814.

48. Koller M, Salerno A, Dias M, Reiterer A, Braunegg G: Modern biotechnological polymer synthesis: a review. Food Technol Biotechnol 2010, 48(3):255-269.

49. Ciccarelli FD, von Mering C, Suyama M, Harrington ED, lzaurralde E, Bork P: Complex genomic rearrangements lead to novel primate gene function. Genome Res 2005, 15(3):343-351.

50. Singh AH, Doerks T, Letunic I, Raes J, Bork P: Discovering functional novelty in metagenomes: examples from light-mediated processes. J Bacteriol 2009, 191(1):32-41.

51. Pohlmann A, Fricke WF, Reinecke $F$, Kusian B, Liesegang $H$, Cramm $R$, Eitinger T, Ewering C, Potter M, Schwartz E, Strittmatter A, Voss I, Gottschalk $G$, Steinbüchel A, Friedrich B, Bowien B: Genome sequence of the bioplastic-producing "Knallgas" bacterium Ralstonia eutropha $\mathrm{H} 16$. Nat Biotechnol 2006, 24(10):1257-1262.

52. Jin H, Nikolau BJ: Role of genetic redundancy in polyhydroxyalkanoate (PHA) polymerases in PHA biosynthesis in Rhodospirillum rubrum. J Bacteriol 2012, 194(20):5522-5529.

53. Quelas Jl, Mongiardini EJ, Perez-Gimenez J, Parisi G, Lodeiro AR: Analysis of two polyhydroxyalkanoate synthases in Bradyrhizobium japonicum USDA 110. J Bacteriol 2013, 195(14):3145-3155

54. Urakawa H, Martens-Habbena W, Stahl DA: High abundance of ammoniaoxidizing Archaea in coastal waters, determined using a modified DNA extraction method. Appl Environ Microbiol 2010, 76(7):2129-2135.

55. Zhou J, Bruns MA, Tiedje JM: DNA recovery from soils of diverse composition. Appl Environ Microbiol 1996, 62(2):316-322.

56. Altschul SF, Madden TL, Schaffer AA, Zhang J, Zhang Z, Miller W, Lipman DJ: Gapped BLAST and PSI-BLAST: a new generation of protein database search programs. Nucleic Acids Res 1997, 25(17):3389-3402.

57. Artimo P, Jonnalagedda M, Arnold K, Baratin D, Csardi G, de Castro E, Duvaud S, Flegel V, Fortier A, Gasteiger E, Grosdidier A, Hernandez C, 
loannidis V, Kuznetsov D, Liechti R, Moretti S, Mostaguir K, Redaschi N,

Rossier G, Xenarios I, Stockinger H: ExPASy: SIB

bioinformatics resource portal. Nucleic Acids Res 2012,

40(Web Server issue):W597-W603.

58. Edgar RC: MUSCLE: multiple sequence alignment with high accuracy and high throughput. Nucleic Acids Res 2004, 32(5):1792-1797.

59. Hall TA: BioEdit: a user-friendly biological sequence alignment editor and analysis program for Windows 95/98/NT. Nucleic Acids Symp Ser 1999, 41:95-98.

60. Tamura K, Peterson D, Peterson N, Stecher G, Nei M, Kumar S: MEGA5: molecular evolutionary genetics analysis using maximum likelihood, evolutionary distance, and maximum parsimony methods. Mol Biol Evol 2011, 28(10):2731-2739.

61. Uchiyama T, Watanabe K: Improved inverse PCR scheme for metagenome walking. BioTechniques 2006, 41(2):183-188.

62. Borujeni A, Channarasappa AS, Salis HM: Translation rate is controlled by coupled trade-offs between site accessibility, selective RNA unfolding and sliding at upstream standby sites. Nucleic Acids Res 2013, 42(4):2646-2659.

63. Kovach ME, Elzer PH, Hill DS, Robertson GT, Farris MA, Roop RM 2nd, Peterson KM: Four new derivatives of the broad-host-range cloning vector $\mathrm{pBBR} 1 \mathrm{MCS}$, carrying different antibiotic-resistance cassettes. Gene 1995, 166(1):175-176.

64. Simon R, Priefer U, Puhler A: A broad host range mobilization system for in vivo genetic engineering: transposon mutagenesis in Gram negative bacteria. Nat Biotech 1983, 1(9):784-791.

65. Friedrich $B$, Hogrefe $C$, Schlegel $\mathrm{H}$ : Naturally occurring genetic transfer of hydrogen-oxidizing ability between strains of Alcaligenes eutrophus. J Bacterio/ 1981, 147(1):198-205.

66. Braunegg G, Sonnleitner B, Lafferty RM: A rapid gas chromatographic method for the determination of poly- $\beta$-hydroxybutyric acid in microbial biomass. Eur J Appl Microbiol Biotechnol 1978, 6(1):29-37.

\section{Submit your next manuscript to BioMed Central and take full advantage of:}

- Convenient online submission

- Thorough peer review

- No space constraints or color figure charges

- Immediate publication on acceptance

- Inclusion in PubMed, CAS, Scopus and Google Scholar

- Research which is freely available for redistribution 